\title{
Difference in Patient Outcomes Coming From Public and Private Hospitals in an Intensive Care Unit in Brazil
}

\author{
Fabio F Amorim ${ }^{\mathrm{a}, \mathrm{e}}$, Adriell R Santana ${ }^{\mathrm{a}}$, Rodrigo S Biondi ${ }^{\mathrm{b}}$, Alethea PP Amorim ${ }^{\mathrm{c}}$, \\ Edmilson B Moura $^{\mathrm{d}}$, Karlo J Quadros ${ }^{\mathrm{a}}$, Humberto S Oliveira ${ }^{\mathrm{b}}$, Rubens AB Ribeiro ${ }^{\mathrm{b}}$
}

\begin{abstract}
Background: Compare demographic data, mortality and intensive care unit length of stay (ICU LOS) in patients coming from public hospitals of the Brazilian Unified Health System and patients coming from private hospitals of the Brazilian Supplementary Health System in a single private general ICU.
\end{abstract}

Methods: A retrospective cohort study was performed on patients in the ICU of Hospital Anchieta in Brasilia, DF, Brazil, over a period of 2 years. The patients were divided into 2 groups: patients from public hospitals of the Unified Health System group (PUBH, $\mathrm{N}=75$ ) and patients from private hospitals of the Brazilian Supplementary Health System group (PRIH, N =1,614).

Results: In total, 1,689 patients were admitted. For the entire cohort, the median age was $62 \pm 17$ years, and the mean APACHE II score was $13 \pm 7$. The PUBH had a higher APACHE II score (18 \pm 9 versus $12 \pm 7, \mathrm{P}=0.00)$, were younger $(53 \pm 2$ versus $63 \pm 16$ years, $\mathrm{P}=0.00)$, and had higher incidence of circulatory shock (19.2 versus $11.4 \%, \mathrm{P}=0.01$ ), and kidney injury or renal failure (38.4 versus $25.5 \%, \mathrm{P}=0.01)$ at the time of ICU admission, compared to the PRIH. The ICU LOS was longer for the PUBH compared to the PRIH (18 \pm 18 versus $6 \pm 14$ days, $\mathrm{P}=0.00)$. The overall mortality rate was higher for the PUBH compared to the PRIH (33.3 versus $9.7 \%, \mathrm{P}=0.00)$.

Conclusions: In a single ICU, where patients had access to the

Manuscript accepted for publication October 11, 2012

${ }^{a}$ Faculty of Medicine, Escola Superior de Ciencias da Saude, Brasilia, DF, Brazil

${ }^{\mathrm{b}}$ Adult Intensive Care Unit, Hospital Anchieta, Brasilia, DF, Brazil

${ }^{\mathrm{c}}$ Centro de Ensino e Tecnologia em Ciencias da Saude, Brasilia, DF, Brazil

dAdult Intensive Care Unit, Hospital de Base do Distrito Federal, Brasilia, DF, Brazil

${ }^{\mathrm{e}}$ Corresponding author: Fabio F Amorim, Coordenacao de Pesquisa e Comunicacao Cientifica. SMHN Quadra 03, conjunto A, Bloco 1, Edifício FEPECS, Brasilia, DF, Brazil. Email: ffamorim@gmail.com

doi: http://dx.doi.org/10.4021/jocmr1157w same human and technological resources, patients from the PUBH had a higher APACHE II score, ICU LOS, and mortality rate than those from the PRIH.

Keywords: Intensive care units; Health inequalities; Outcomes; Mortality; National health system; Private health system

\section{Introduction}

The Brazilian Health System consists of a complex network of a public sector, called the Unified Health System (SUS), which is financed by the state at the federal, state, and municipal levels, and a private sector, called the Supplementary Health System, which is financed by employers and/or households and includes group medicine, medical cooperatives, and insurance companies $[1,2]$. The Constitution of the Federative Republic of Brazil in 1988 stated that the Brazilian Health System should be based on the principles of equality, universality, and comprehensive care for all Brazilian citizens [3]. However, as was observed in other countries that have adopted a similar model, the existence of an additional private sector brings a great challenge, which is the inequality in access to health care $[1,2,4]$.

Patients with access to private services have higherquality health care, which can be observed in the intensive care units (ICUs), where studies have shown better outcomes for private hospitals compared to public hospitals $[5,6]$. The private hospitals compared to the public hospitals usually have greater access to technological and human resources. This factor has been implicated as the cause of this difference in performance [5]. However, there are no studies that compare the outcomes of patients from public and private hospitals admitted to a single ICU, where they had access to the same human and technological resources.

The main purpose of this study was to compare the mortality of patients coming from public and private hospitals admitted to a single ICU. Simultaneously, we assessed the intensive care unit length of stay (ICU LOS), demographic data, and the presence of circulatory shock, and kidney injury or renal failure at the time of ICU admission. 
Table 1. Baseline Demographics of Patients in the Unified Health System Group (PUBH) and the Supplementary Health System Group (PRIH)

\begin{tabular}{lllll}
\hline & & $\begin{array}{l}\text { PUBH } \\
(\mathbf{N}=\mathbf{7 5})\end{array}$ & $\begin{array}{l}\text { PRIH } \\
(\mathbf{N}=\mathbf{1 , 6 1 4})\end{array}$ & P-value \\
\hline Age (years) & Mean (SD) & $53(22)$ & $63(16)$ & $0.00^{*}$ \\
APACHE II & Mean (SD) & $18(9)$ & $12(7)$ & $0.00^{*}$ \\
Male & $\%$ & 45.3 & 55.8 & 0.05 \\
Medical diagnosis & $\%$ & 97.3 & 51.3 & $0.00 *$ \\
Kidney injury or renal failure & $\%$ & 38.4 & 25.5 & $0.01 *$ \\
Circulatory shock & $\%$ & 19.2 & 11.4 & $0.04 *$ \\
\hline
\end{tabular}

The differences were compared using the Student's t-test, Wilcoxon-Mann-Whitney $U$ test, and Chi-square test $\left(X^{2}\right)$ where appropriate. *Statistical significance $\mathrm{P}<0.05$. APACHE II = Acute Physiology and Chronic Health Evaluation II, $\mathrm{SD}=$ Standard Deviation.

\section{Methods}

\section{Study design and setting}

This was a retrospective cohort study conducted from January 2008 to December 2009, involving all adult patients admitted consecutively to the ICU of Hospital Anchieta, a tertiary care private hospital with 140 beds and 24 ICU beds ICU, located in Brasilia, DF, Brazil.

The Ethics Committee of Hospital Anchieta approved the study and waived the need for informed consent. The conduction of the study did not interfere with patient management decisions.

\section{Subjects}

All of the patients were admitted to the ICU during the study period. Patients younger than 18 years old, transferred from another ICU, readmitted during the same hospitalization, or transferred to another ICU were excluded from the study.

\section{Measurements and outcome evaluation}

Patients were divided into two groups: patients coming from public hospitals of the Unified Health System group (PUBH) and patients coming from private hospitals of the Supplementary Health System group (PRIH).

All of the patients had an APACHE II score computed within 24 hours of admission. Each participant was followed until the ICU discharge or death. We also recorded demographic data, mortality, ICU LOS, and the presence of circulatory shock, and kidney injury or renal failure according to the RIFLE classification [7] at the time of ICU admission.

\section{Statistical analysis}

The Kolmogorov-Smirnov test was used to assess the normality of the data. Continuous variables with a normal dis-

Table 2. Outcomes of Patients in the Unified Health System Group (PUBH) and the Supplementary Health System Group (PRIH)

\begin{tabular}{lllll}
\hline & & $\begin{array}{l}\text { PUBH } \\
(\mathbf{N}=\mathbf{7 5})\end{array}$ & $\begin{array}{l}\text { PRIH } \\
(\mathbf{N}=\mathbf{1 , 6 1 4})\end{array}$ & P-value \\
\hline ICU LOS (days) & Mean (SD) & $18(18)$ & $6(14)$ & $0.00^{*}$ \\
Mortality & $\%$ & 33.3 & 9.7 & $0.00^{*}$ \\
\hline
\end{tabular}

The differences were compared using the Student's t-test and chi-square test $\left(X^{2}\right)$ where appropriate. *Statistical significance $\mathrm{P}<0.05$. ICU LOS = intensive care unit length of stay, SD = Standard Deviation. 
Table 3. Baseline Demographics of Patients With a Medical Diagnosis in the Unified Health System Group (PUBH) and the Supplementary Health System Group (PRIH).

\begin{tabular}{lllll}
\hline & & $\begin{array}{l}\text { PUBH } \\
(\mathbf{N}=\mathbf{7 3})\end{array}$ & $\begin{array}{l}\text { PRIH } \\
(\mathbf{N}=\mathbf{8 3 6})\end{array}$ & P-value \\
\hline Age (years) & Mean (SD) & $52(22)$ & $64(18)$ & $0.01^{*}$ \\
APACHE II & Mean (SD) & $18(9)$ & $15(8)$ & $0.00^{*}$ \\
Male & $\%$ & 45.2 & 53.5 & 0.18 \\
Kidney injury or renal failure & $\%$ & 43.7 & 43.0 & 0.51 \\
Circulatory shock & $\%$ & 19.7 & 11.3 & $0.03 *$ \\
\hline
\end{tabular}

The differences were compared using Student's t-test, Wilcoxon-Mann-Whitney $U$ test, and chi-square test $\left(X^{2}\right)$ where appropriate. *Statistical significance $\mathrm{P}<0.05$. APACHE II = Acute Physiology and Chronic Health Evaluation II, SD = Standard Deviation .

tribution were compared using Student's t-test. Continuous variables without a normal distribution were compared using the Wilcoxon-Mann-Whitney U test. Categorical parameters were compared using the Chi-square test $\left(\chi^{2}\right)$. The level of significance was set at $5 \%(\mathrm{P}<0.05)$. All of the analyses were performed using the Statistical Package for Social Sciences 17.0 for Windows (SPSS 17.0 for Windows, SPSS Inc., Chicago, Illinois, USA).

\section{Results}

Among the 1,689 patients included in the study, 183 patients came from public hospitals of the Brazilian Unified Health System (11\%) and 1,467 patients came from private hospitals of the Brazilian Supplementary Health System (89\%). For the entire cohort, the mean APACHE II score was $13 \pm$ 7 , the median age was $62 \pm 17$ years, and 935 patients were male (55.4\%). The PUBH had a higher APACHE II score (18 \pm 9 versus $12 \pm 7, \mathrm{P}=0.00)$, were younger $(53 \pm 22$ versus 63 \pm 16 years, $\mathrm{P}=0.00)$, and had a higher incidence of circulatory shock (19.2 versus $11.4 \%, \mathrm{P}=0.04)$, and kidney injury or renal failure $(38.4$ versus $25.5 \%, \mathrm{P}=0.01$ ) at the time of ICU admission compared to the PRIH. There were more admissions for a medical diagnosis from the PUBH than the PRIH (97.3 versus 51.3\%, P=0.00) (Table 1). The ICU LOS was longer for the PUBH compared to the PRIH $(18 \pm 18$ versus $6 \pm 14$ days, $\mathrm{P}=0.00)$. The mortality rate was higher for the PUBH compared to the PRIH (33.3 versus 9.7\%, P $=0.00$ ) (Table 2). Analyzing only the medical patients, the PUBH still had a higher APACHE II score $(18 \pm 9$ versus $15 \pm 8, \mathrm{P}=0.00)$ and were younger $(52 \pm 22$ versus $64 \pm 18$ years, $\mathrm{P}=0.01$ ) compared to the PRIH. At the time of ICU admission, the PUBH had a higher incidence of circulatory shock (19.7 versus $11.3 \%, \mathrm{P}=0.03)$ compared to the PRIH, but there were no difference between the groups regarding kidney injury or renal failure (43.7 versus $43.0 \%, \mathrm{P}=0.51)$ (Table 3). The ICU LOS was longer for the PUBH compared to the PRIH ( $18 \pm 18$ versus $9 \pm 18$ days, $\mathrm{P}=0.00)$. The mortality rate was higher for the PUBH compared to the PRIH

Table 4. Outcomes of Patients With a Medical Diagnosis in the Unified Health System Group $(\mathrm{PUBH})$ and the Supplementary Health System Group $(\mathrm{PRIH})$

\begin{tabular}{lcccc}
\hline & PUBH & PRIH & P-value \\
& & $(\mathbf{N}=\mathbf{7 3})$ & $(\mathbf{N}=\mathbf{8 3 6})$ & \\
\hline ICU LOS (days) & Mean (SD) & $18(18)$ & $9(18)$ & $0.00 *$ \\
Mortality & $\%$ & 33.8 & 17.1 & $0.00 *$ \\
\hline
\end{tabular}

The differences were compared using the Student's t-test and Chi-square test $\left(X^{2}\right)$ where appropriate. *Statistical significance $\mathrm{P}<0.05$. ICU LOS = intensive care unit length of stay, SD = Standard Deviation. 
(33.8 versus $17.1 \%, \mathrm{P}=0.00)$ (Table 4$)$

\section{Discussion}

In this study of admissions in a single ICU, patients coming from the SUS were younger but presented with more severe disease compared to patients coming from the Supplementary Health System at the time of admission. There was also a higher rate of circulatory shock, and kidney injury or renal failure among patients coming from the SUS, who had a longer hospital stay and higher mortality rate compared to patients coming from the Supplementary Health System. Hospitalization for a medical diagnosis was more common in patients from the SUS, which accounted for almost all of the cases in this group (97.3\%). Thus, we opted to conduct an analysis only with patients with a clinical diagnosis. Even in this analysis, patients from the SUS had a higher mortality rate and ICU LOS compared to patients coming from the Supplementary Health System.

Silva and colleagues published data from a cohort study [5] conducted in patients hospitalized for sepsis in five mixed ICUs of private and public hospitals in Brazil. That study observed a higher mortality for patients from the public hospitals compared to those from private hospitals, even if no significant differences were observed in the APACHE II score of these patients, suggesting that these differences could be related to factors including the differences in technological and human resources between the private and public hospitals.

Another study performed by Ferreira and colleagues [6] comparing mortality and morbidity in patients with acute myocardial infarction hospitalized in public and private hospitals in Feira de Santana, BA, Brazil observed that patients in the private hospitals showed a markedly low mortality rate, comparable to the rates in countries with a high per capita income. However, the mortality rate in public hospitals was high, even above the mortality rate in countries with a worse per capita income than Brazil.

Nevertheless, this fact is similar to that observed in other Latin America countries, such as Colombia, where a survey study conducted by Perez and colleagues [8] in 20 ICUs showed a marked difference between the public and private sectors, where all four of the ICUs with the lowest mortality ratio belonged to private hospitals, while four of five ICUs with the highest mortality belonged to public hospitals.

Unlike these previous studies, this study was conducted in a single ICU with patients from the public and private sectors, who had access to the same technological and human resources. This suggests that other factors before ICU admission are also involved in this phenomenon. It is known that various conditions can influence patient outcomes in the ICU setting, including the delay to ICU admission and preexisting conditions, such as nutritional status [9-14].

An important factor is the time elapsed between the admission request and ICU admission [14-18]. It has been shown that the delay in establishing specialized care affects patient outcomes, especially when adequate treatment is not instituted quickly as early goal-directed therapies [17-18]. Furthermore, there is a window of opportunity to implement these treatments. Additionally, patient transfers to the ICU do not lead to improved patient outcomes [19]. In a study designed to assess the impact of delayed patient transfer from the emergency department to the ICU, Chalfin and colleagues [15] showed that patients who take more than six hours to be transferred to the ICU had an increased hospital length of stay and higher ICU and hospital mortalities. A similar result was observed in a study conducted in Brazil [16]. Another Brazilian study conducted on surgical patients by Chiavone and Rasslan [14] has observed that the delay between the end of a surgery and ICU admission was associated with a worse APACHE II score and mortality rate. All of these factors must be related to the findings of our study.

A positive aspect of our study was the ability to compare the clinical outcomes of the patient groups in which the monitoring and the treatment have been standardized in a single ICU because, otherwise, the initial treatments would most likely have been so different. Thus, we conclude that the impact on patient morbidity and mortality can be attributed not only to the quality of care in an ICU but also to other factors, such as the health system in which the ICU is located. It is well known that, in public hospitals in Brazil, the conditions for the appropriate treatment of critically ill patients are insufficient due to the high influx of patients, lack of resources, and lack of trained staff [20]. Measures to ensure an appropriate early treatment in an emergency environment for critically ill patients could result in significant decreases in mortality and a subsequent reduction in costs. Recent studies have shown that training and supporting appropriate emergency professionals in the care of critically ill patients, especially patients with severe sepsis or septic shock, to be cost effective [21-22].

\section{Conclusion}

In a single intensive care unit, where the patients had access to the same human and technological resources, the PUBH had a higher APACHE II score and mortality compared to the PRIH. Thus, we conclude that morbidity and mortality of these patients can be attributed not only to the quality of care in an ICU but also to other factors, such as the health system in which the ICU is located. Future studies are needed to investigate the determinants of these findings, such as the social and economic aspects and the delay to ICU admission.

\section{Acknowledgement}

ARS is research scholar from FEPECS (Fundacao de En- 
sino e Pesquisa da Secretaria de Saude do Distrito Federal), Brasilia, DF, Brazil.

\section{Declaration}

This work was performed in the Adult Intensive Care Unit at Hospital Anchieta in Brasilia, DF, Brazil.

\section{References}

1. Santos IS, Uga MA, Porto SM. [The public-private mix in the Brazilian Health System: financing, delivery and utilization of health services]. Cien Saude Colet. 2008;13(5):1431-1440.

2. Paim J, Travassos C, Almeida C, Bahia L, Macinko J. The Brazilian health system: history, advances, and challenges. Lancet. 2011;377(9779):1778-1797.

3. Constituicao da Republica Federativa do Brasil: de 5 outubro de 1988. Sao Paulo: Editora Atlas; 1988.

4. Rodriguez M, Stoyanova A. The effect of private insurance access on the choice of GP/specialist and public/ private provider in Spain. Health Econ. 2004;13(7):689703.

5. Silva E, Pedro Mde A, Sogayar AC, Mohovic T, Silva CL, Janiszewski M, Cal RG, et al. Brazilian Sepsis Epidemiological Study (BASES study). Crit Care. 2004;8(4):R251-260.

6. Ferreira GM, Correia LC, Reis H, Ferreira Filho CB, Freitas F, Junior I, Oliveira N, et al. Increased mortality and morbidity due to acute myocardial infarction in a public hospital, in Feira de Santana, Bahia. Arq Bras Cardiol. 2009;93(2):97-104.

7. Bellomo R, Ronco C, Kellum JA, Mehta RL, Palevsky P. Acute renal failure - definition, outcome measures, animal models, fluid therapy and information technology needs: the Second International Consensus Conference of the Acute Dialysis Quality Initiative (ADQI) Group. Crit Care. 2004;8(4):R204-212.

8. Perez A, Dennis RJ, Rondon MA, Metcalfe MA, Rowan KM. A Colombian survey found intensive care mortality ratios were better in private vs. public hospitals. J Clin Epidemiol. 2006;59(1):94-101.

9. Sales Junior JA, David CM, Hatum R, et al. An epidemiological study of sepsis in Intensive Care Units: Sepsis Brazil study. Rev Bras Ter Intensiva. 2006; 18(1):9-10.

10. Gregory CJ, Marcin JP. Golden hours wasted: the human cost of intensive care unit and emergency department inefficiency. Crit Care Med. 2007;35(6):1614-1615.

11. Abelha FJ, Castro MA, Landeiro NM, Neves AM, Santos CC. [Mortality and length of stay in a surgical inten- sive care unit.]. Rev Bras Anestesiol. 2006;56(1):34-45.

12. Higgins TL. Quantifying risk and benchmarking performance in the adult intensive care unit. J Intensive Care Med. 2007;22(3):141-156.

13. Higgins TL, McGee WT, Steingrub JS, Rapoport J, Lemeshow S, Teres D. Early indicators of prolonged intensive care unit stay: impact of illness severity, physician staffing, and pre-intensive care unit length of stay. Crit Care Med. 2003;31(1):45-51.

14. Chiavone PA, Rasslan S. Influence of time elapsed from end of emergency surgery until admission to intensive care unit, on Acute Physiology and Chronic Health Evaluation II (APACHE II) prediction and patient mortality rate. Sao Paulo Med J. 2005;123(4):167-174.

15. Chalfin DB, Trzeciak S, Likourezos A, Baumann BM, Dellinger RP. Impact of delayed transfer of critically ill patients from the emergency department to the intensive care unit. Crit Care Med. 2007;35(6):1477-1483.

16. Cardoso LT, Grion CM, Matsuo T, Anami EH, Kauss IA, Seko L, Bonametti AM. Impact of delayed admission to intensive care units on mortality of critically ill patients: a cohort study. Crit Care. 2011;15(1):R28.

17. Rivers E, Nguyen B, Havstad S, Ressler J, Muzzin A, Knoblich B, Peterson E, et al. Early goal-directed therapy in the treatment of severe sepsis and septic shock. N Engl J Med. 2001;345(19):1368-1377.

18. Jansen TC, van Bommel J, Schoonderbeek FJ, Sleeswi$\mathrm{jk}$ Visser SJ, van der Klooster JM, Lima AP, Willemsen SP, et al. Early lactate-guided therapy in intensive care unit patients: a multicenter, open-label, randomized controlled trial. Am J Respir Crit Care Med. 2010;182(6):752-761.

19. Simchen E, Sprung CL, Galai N, Zitser-Gurevich Y, Bar-Lavi Y, Gurman G, Klein M, et al. Survival of critically ill patients hospitalized in and out of intensive care units under paucity of intensive care unit beds. Crit Care Med. 2004;32(8):1654-1661.

20. Rezende E, Silva JM, Jr., Isola AM, Campos EV, Amendola CP, Almeida SL. Epidemiology of severe sepsis in the emergency department and difficulties in the initial assistance. Clinics (Sao Paulo). 2008;63(4):457-464.

21. Koenig A, Pincon PD, Feijo J, et al. Estimate of the economic impact of implementing an in hospital protocol for the early detection and treatment of severe sepsis in public and private hospitals in southern Brazil. Rev Bras Ter Intensiva 2010, 22(3):213-219.

22. Ferrer R, Artigas A, Levy MM, Blanco J, GonzalezDiaz G, Garnacho-Montero J, Ibanez J, et al. Improvement in process of care and outcome after a multicenter severe sepsis educational program in Spain. JAMA. 2008;299(19):2294-2303. 